\title{
Nutrition Interventions for Healthy Ageing in Indonesia
}

\author{
Luciana Sutanto, Widjaja Lukito, Ray Wagiu Basrowi*
}

Background: Including Indonesia, the elderly population worldwide is on the rise. This situation is closely related to the increase in the incidence and prevalence of non-communicable diseases. Eating behavior is related to the risk of noncommunicable Disease (NCDs) in the elderly. Therefore, nutrition intervention should be carried out from old age.

Objectives: The purpose of this study is to review potential nutritional interventions to prepare for a healthy ageing process in an Indonesian context.

Discusion: This review uses social cognition theory to emphasize the importance of nutrition education, the development of nutritional products with biologically active compounds, and practical guidelines that influence individual dietary behavior. Nutritional interventions should take into account Indonesia's existing food-based balanced nutrition diet guidelines and the dietary patterns of adults and the elderly. Indonesia has a large population, ethnic and cultural diversity, which together affect people's daily consumption of various foods.

Conclusions: Customized nutrition education programs and the development of functional foods are appropriate interventions that can be implemented in Indonesia.

Keywords: healthy ageing, nutrition intervention, adult, elderly, preventive, Indonesia

\author{
*Correspondent: \\ Ray.basrowi1@danone.com \\ Ray Wagiu Basrowi \\ Danone Specialized Nutrition Indonesia
}

\section{INTRODUCTION}

The world population is ageing. The World Health Organization (WHO) reported the increase of global life expectancy by 5.5 years between 2000 and $2016^{1}$. This also applies to Indonesia, in which the average life expectancy was increased from 66.1 years in 2000 to 69.3 in $2016^{1}$ With these extra lives, we hope that there will be more and more elderly people worldwide, including Indonesia. The United Nations (UN) uses 60+ years as the cutoff for elderly and above 80 years as the oldest-old ${ }^{2}$. According to the Law No 13 Year 1998, age $60+$ years is used as threshold to define elderly ${ }^{3} . \ln 2019$, Indonesia is home to 25.64 million elderly or equivalent to $9.6 \%$ of the total population. It is estimated that by 2035 , the elderly population will nearly triple $(48.2$ million) ${ }^{4}$. The additional number will come from an adult population over 45 years old, so interventions should target this adult population. Although advances in health technology can extend lifespan, most scientists are committed to ensuring healthy ageing by preventing age- related diseases.

Ageing is a complex process characterized by physical and psychological changes. These physiological changes include decreased sensory perception, malabsorption, and increased risk of metabolic syndrome. As people get older, their sense of smell and taste diminishes ${ }^{5}$ due to many underlying deficiencies. More than $50 \%$ of people over 65 have severe smell disorders. ${ }^{5}$ In addition, they may have difficulty chewing food. In a survey conducted in Hong Kong for more than
60 years, about $37.8 \%$ of people have chewing problems ${ }^{6}$. Dry mouth symptoms were also common among in the elderly ${ }^{7}$. In addition, as we age, the function of the gastrointestinal tract may change, and decrease gastric emptying rate ${ }^{8}$. All these factors may affect appetite and food intake.

Generally, people think about aging at the age of 60 , and suffer from age-related diseases due to the aging process. Non-communicable diseases (NCD) are common in the elderly, and include osteoporosis/osteoporosis, sarcopenia, metabolic syndrome, cerebrovascular diseases and cancer. The prevalence of NCDs in Indonesia is increasing over the years, and it causes two-third of mortality. ${ }^{9}$ The incidence of NCDs is not resulted from an instant process, but it derives from long-term poor habits when individuals were still in the adult age. Middle age refers to people between the ages of 40 and 60 , and usually marks as the beginning of age. It is well documented that the physical and psychological changes of middleaged people will potentially affect the health of individuals in their later years.

Nutrition plays an important role in achieving healthy ageing. Habitual food consumption is related to nutritional status and becomes the main determinant of non-communicable diseases ${ }^{10}$. The evaluation of eating patterns is used to describe the changes caused by different demographic and sociocultural backgrounds. Eating patterns may vary among different groups of people based on age categories or cultural aspects. The purpose of this study is to review potential nutritional 
interventions to prepare for a healthy ageing process in an Indonesian context. This review uses social cognition theory to emphasize the importance of nutrition education, the development of nutritional products with biologically active compounds, and practical guidelines that influence individual dietary behavior.

\section{RESULT AND DISCUSSION}

\section{Existing Food-based Dietary Guideline in Indonesia}

Food-based dietary guidelines (FBDG) are a universal tool that can be used to translate evidencebased nutrition into cultural practices. In 1993, Indonesia introduced the general guidelines for a balanced diet or known as "Pedoman Umum Gizi Seimbang" (PUGS). Since the implementation of PUGS was not optimal, PUGS was then revised in 2014, and renamed as balanced diet guidelines or "Pedoman Gizi Seimbang" (PGS) ${ }^{11}$. This guideline consists of four pillars, namely 1 ) consuming variety of foods; 2) supporting self-hygiene behavior; 3 ) being active by participating in sports activities; and 4) maintaining a normal weight ${ }^{12}$. The guidelines not only convey health messages to ordinary people, but also convey health messages to the elderly. The information for the elderly will be adjusted according to the physiological changes and nutritional problems in the ageing process. Such as reducing bone density, reducing organ function, taste and smell problems. The FBDG for the elderly contains the following information: 1) Be familiar with the intake of fish and milk to reduce the risk of bone density reduction; 2) Eat enough fiber-rich foods; 3) Drink plenty of water; 4) Maintain physical exercise ; 5) Limit the consumption of sugar, salt and fat ${ }^{13}$. However, the guidelines have not been implemented well among the elderly. Generally, Indonesians are not used to reading nutrition facts on food labels. People pay more attention to the brand, expiration date, and halal status of food. The information in the guidelines is still generic and does not mention the targets for specific nutrients (such as total dietary fiber). In addition, there are no specific targets regarding the frequency and duration of physical activity. Therefore, FBDG targeting the elderly is still considered insufficient and has not been properly implemented ${ }^{14}$.

\section{Dietary patterns among the adult and elderly}

As we all know, a healthy diet can reduce the risk of disease. When we discuss healthy eating, the existing Indonesian FBDG recommends a balanced diet, which is characterized by a certain amount of food in each meal. No one eats only one food or nutrition. People usually eat a variety of foods in one meal and practice specific ways throughout the day. There are many studies on diet structure and healthy aging. A study in the United States found that a high score on the Healthy Eating Index was associated with a reduction in overall mortality and cardiovascular disease mortality ${ }^{15}$. A cohort study of people aged 3075 and over 65 years old showed that those who consume a lot of vegetables, fruits, whole grains, low-fat dairy products, poultry and fish have lower mortality and higher quality of life $\mathrm{e}^{16,{ }^{17}}$. A similar study conducted among young people (over 45 years old) also found that large amounts of fruits, vegetables, and foods with high protein content are associated with a lower likelihood of memory loss ${ }^{18}$. Another study showed that adhering to thetraditional Mediterranean diet canreduce overall mortality and neoplastic diseases ${ }^{19,20}$. The Mediterranean diet is widely popular in European Mediterranean countries and has been proven to be effective, but whether it is effective for other populations is still questionable. The Mediterranean diet is characterized by a large amount of plant-based foods, mainly fruits and vegetables, grains, herbs, nuts, legumes, and whole grains. Kouris-Blazos et al. pointed out that as long as people follow the traditional Mediterranean diet principles, the overall risk of death will be reduced. This is evident among the Anglo-Celtic and comparable to the Greek-Australian population ${ }^{21}$. However, considering the cultural background, the eating habits of Asians may be different from those of the European Mediterranean. Bin et al. found that the dietary habits of Chinese in North China are different from the Mediterranean diet, and therefore more similar to the American population. The cholesterol and unsaturated fatty acids were significantly higher and fiber intake was lower than those living in Mediterranean regions ${ }^{22}$. The debate about which diet best meets the health status of the elderlycontinues.

In Indonesian context, protein consumption is considerably low, highest at $12 \%$ of the total daily energy intake. This level of protein consumption should be increased to at least $15 \%{ }^{23}$. Therefore, it will reduce carbohydrate consumption. In general, the carbohydrate consumption pattern in Indonesia is still dominated by rice, which is $1.57 \mathrm{~kg}$ per week, which is much higher than other types of food such as wheat, corn or cassava ${ }^{24}$. High carbohydrate consumption is usually accompanied by an increase in monosaccharide intake, reaching the level recommended by the World Health Organization on the total daily monosaccharide intake ${ }^{10,25,26}$. A study evaluated the eating habits of the elderly in Jakarta and found that most people reduced their intake of meat, chicken, eggs, fat, fish and rice/noodles/bread. The consumption of vegetables and fruits is relatively stable. Additionally, the elderly is seldom to consume fast food or so-called trendy food ${ }^{27}$. In general, binge eating is not a problem among the elderly population in Indonesia. Therefore, nutritional deficiencies should be considered because Indonesian elderly people generally consume less traditional foods and are more interested in traditional foods compared to Western or fast foods.

\section{Dietary behavior changes as the aim of nutrition intervention}

Nutrition is part of the investment to improve the quality of life of the elderly. Adopting balanced dietary interventions in adulthood can prevent the risk of specific age-related diseases ${ }^{28}$. The conceptual framework is used to map all the risks of eating behavior and plan potential interventions. 


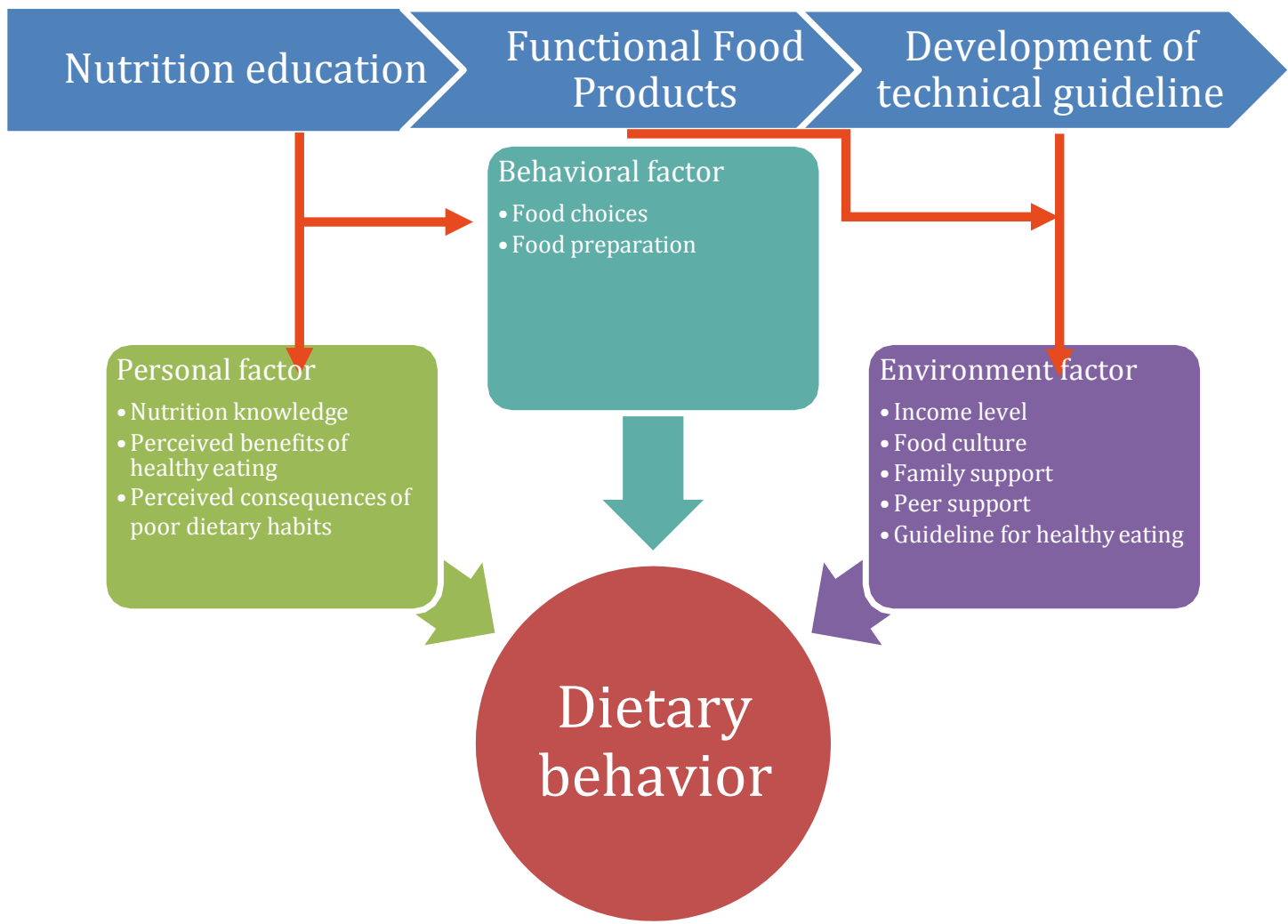

Figure 1. Dietary Behavior conceptual framework based on social cognitive theory Source: Modified social cognitive theory

Using social cognitive theory (SCT), we identified various factors that influence elderly's dietary behavior ${ }^{29,30}$. The SCT reflects the interaction ofpersonal, behavior, and environment that determine person's choice of action. Personal knowledge, self-efficacy and beliefs will affect the behavior of choosing healthy food. Social environmental factors such as income level, family and peer support can also affect eating behavior.

\section{Nutrition education}

Nutrition education is necessary to achieve healthy elderly people. However, what is worrying is that interventions are toolate to prevent age-related diseases. In order to prepare for healthy aging, nutrition education should be carried out before the population enters the critical age of the elderly. It can be seen from the theory of social cognition that an individual's understanding of nutrition, the perceived benefits of healthy eating, and the consequences of poor eating habits will affect an individual's eating behavior. Many nutrition programs provide general information on how to prepare food and choose various foods. However, only limited interventions have been developed for specific elderly or elderly populations. Facts have proved that tailor-made nutrition education is effective for maintaining healthy behavior changes ${ }^{31}$

In Indonesia, the nutrition education plan should be adjusted according to the local situation, because the local food varies greatly ${ }^{32}$. The type of food is affected by the types of products available on the market and the availability of prices. The main staple food of most
Indonesians is rice. However, for some populations, rice is not common, and cassava is more suitable for people living in eastern Indonesia. For religious reasons, many cultures prohibit the use of pork, but in some areas, pork consumes more pork than beef or chicken.

In addition to the local culture, the type of food is also influenced by the place of residence. Compared with rural areas, the living habits and occupations of urban residents are different. Most people who work in cities work in offices, while those who work in rural areas are farmers. Their food types will be affected by different food markets, socioeconomic status and personal characteristics. A case study in West Java compared the food intake of residents in Bandung (urban) and Sumitang (rural) and found different eating patterns. Sedentary workers in urban area tended to obtain energy from grains/tubers, compared to other categories of workers ${ }^{33}$. Individual food choices in Indonesia are usually influenced by the family. It is usually limited to food prepared by the mother. Research shows that there is a positive correlation between maternal and infant nutrition 34,35 . The mother's diet is usually reflected in the child's nutritional status. The role of parents is crucial because it has a great influence on children's eating behavior. Knowledge is the basis for changing personal behavior. Therefore, nutritional knowledge is very important to improve healthy eating behavior. The nutrition education 
plan should be tailored to specific age groups, and pay attention to the local culture, food supply, and family approach.

\section{Functional Food products}

Functional foods are defined as nutritional products containing biologically active compounds that help maintain the best physical, mental, and mental health of the population in herbal/non-herbal form ${ }^{36}$. Indonesia is accustomed to using herbs and herbal products. A national survey shows that the penetration rate of traditional medicines used to treat patients with diabetes or cardiovascular disease is high ${ }^{37}$. Indonesia is rich in natural resources, rich in herbs and spices, and there are more herbal products to explore. Indonesia's famous herb jamu has been widely accepted by the public as a medicine, and its phytopharmacological use has been proven ${ }^{38,39}$. For example, during this COVID-19 pandemic, there is an increasing demand for traditional herbal medicines, which are believed to improve immunity. The potential for developing herbal products is still widespread.

Herbal products can be consumed on their ownor mixed with other ingredients. The use of herbal products is common among adults and the elderly, but still limited among young people. Many companies develop it as an herbal beverage or combine it with milk as a dairy product. The market prefers herbal products because they think natural products are safer than chemical products. This assumption is correct, but it is not entirely correct. Herbal products are complex and contain active agents, but little is known about the safety and efficacy of these products ${ }^{40}$. Just need to do more research on its risks, safety and benefits.

\section{CONCLUSION}

High-quality nutrition is positively correlated with the improvement of health at any stages of life. As Indonesia expects a substantial increase in the elderly population, appropriate nutritional interventions are needed to achieve healthy ageing. Given that ageing is an ongoing process of human life, interventions should be considered in adult life. Customized nutrition education programs and the development of functional foods are appropriate interventions that can be implemented in Indonesian context.

\section{ACKNOWLEDGEMENT}

The author would thank Sari Husada for funding the publication for this article.

\section{REFERENCE}

1. WHO, G. WHO methods for life expectancy and healthy life expectancy. (2014).

2. Sanchez-Niubo, A. et al. Cohort profile: the ageing trajectories of health-longitudinal opportunities and synergies (ATHLOS) project. Int. J. Epidemiol. 48, 1052-1053i (2019).

3. Hu, W.-Y. Elderly immigrants on welfare. J. Hum.
Resour. 711-741 (1998).

Data, P. P. \& Dokumen, P. Kementerian Kesehatan RI. (2014).

5. Boyce, J. M. \& Shone, G. R. Effects of ageing on smell and taste. Postgrad. Med. J. 82, 239-241 (2006).

6. Woo, J., Tong, C. \& Yu, R. Chewing difficulty should be included as a geriatric syndrome. Nutrients 10, 1997 (2018).

7. Schein, O. D. et al. Dry eye and dry mouth in the elderly: a population-based assessment. Arch. Intern. Med. 159, 1359-1363 (1999).

8. Soenen, S., Rayner, C. K., Horowitz, M. \& Jones, K. L. Gastric emptying in the elderly. Clin. Geriatr. Med. 31, 339-353 (2015).

9. RI, K. Laporan Nasional Riskesdas 2018. Jakarta Badan Penelit. dan Pengemb. Kesehat. (2018).

10. Who, J. \& Consultation, F. A. O. E. Diet, nutrition and the prevention of chronic diseases. World Heal. Organ Tech Rep Ser 916, (2003).

11. Kementerian Kesehatan RI. Pedoman gizi seimbang. (2014).

12. Soekirman. Taking the Indonesian nutrition history to leap into betterment of the future generation: development of the Indonesian Nutrition Guidelines. Asia Pac. J. Clin. Nutr. 20, 447-451 (2011).

13. KEMENKES, R. I. Kementerian Kesehatan RI. Bul. Jendela, Data dan Inf. Kesehat. Epidemiol. Malar. di Indones. Jakarta Bhakti Husada (2011).

14. Usfar, A. A. \& Fahmida, U. Do Indonesians follow its dietary guidelines?: evidence related to food consumption, healthy lifestyle, and nutritional status within the period 2000-2010. Asia Pac. J. Clin. Nutr. 20, 484 (2011).

15. Rathod, A. D., Bharadwaj, A. S., Badheka, A. O., Kizilbash, M. \& Afonso, L. Healthy Eating Index and mortality in a nationally representative elderly cohort. Arch. Intern. Med. 172, 275-277 (2012).

16. Anderson, A. L. et al. Dietary patterns and survival of older adults. J. Am. Diet. Assoc. 111, 84-91 (2011).

17. Darmadi-Blackberry, I. et al. Legumes: the most important dietary predictor of survival in older people of different ethnicities. Asia Pac. J. Clin. Nutr. 13, 217-220 (2004).

18. Xu, X., Ling, M., Inglis, S. C., Hickman, L. \& Parker, D. Eating and healthy ageing: a longitudinal study on the association between food consumption, memory loss and its comorbidities. Int. J. Public Health 1-12 (2020).

19. Sofi, F., Macchi, C., Abbate, R., Gensini, G. F. \& Casini, A. Mediterranean diet and health status: an updated meta-analysis and a proposal for a literature-based adherence score. Public Health Nutr. 17, 2769-2782 (2014).

20. Wahlqvist, M. L. et al. Does diet matter for survival in long-lived cultures? Asia Pac. J. Clin. Nutr. 14, (2005).

21. Kouris-Blazos, A. et al. Are the advantages of the Mediterranean diet transferable to other populations? A cohort study in Melbourne, 
Australia. Br. J. Nutr. 82, 57-61 (1999).

22. Bin, F. S., Gradaschi, R. \& Adami, G. F. Mediterranean eating pattern among a Chinese population. Med. J. Nutrition Metab. 9, 149-155 (2016).

23. RI, K. Konsumsi Makanan Individu. Jakarta Kementeri. Kesehat. RI (2014).

24. Saputra, M. F., Firdaus, M. \& Novianti, T. Consumption Patterns of Carbohydrate Sources in Food Secure and Insecure Provinces of Indonesia in 2017. (2019).

25. Organization, W. H. Global status report on noncommunicable diseases 2014. (World Health Organization, 2014).

26. Organization, W. H. Guideline: sugars intake for adults and children. (World Health Organization, 2015).

27. Boedhi-Darmojo, R. Trends in dietary habits of the elderly: The Indonesian case. Asia Pac. J. Clin. Nutr. 11, S351-S354 (2002).

28. Shlisky, J. et al. Nutritional considerations for healthy aging and reduction in age-related chronic disease. Adv. Nutr. 8, 17 (2017).

29. Healthy Hidayanty, M. P. H., Saptawati Bardosono, M. D. \& Rita Damayanti, M. A social cognitive theory-based programme for eating patterns and sedentary activity among overweight adolescents in Makassar, South Sulawesi: a cluster randomised controlled trial. Asia Pac. J. Clin. Nutr. 25, S83 (2016).

30. Mak, T. N. \& Caldeira, S. and Healthy Ageing. (2014).

31. Rolling, T. E. \& Hong, M. Y. The effect of social cognitive theory-based interventions on dietary behavior within children. J Nutr. Heal. Food Sci 4, 1-9 (2016).
32. Wallace, R., Lo, J. \& Devine, A. Tailored nutrition education in the elderly can lead to sustained dietary behaviour change. J. Nutr. Health Aging 20, 8-15 (2016).

33. Dindyal, S. \& Dindyal, S. How personal factors, including culture and ethnicity, affect the choices and selection of food we make. Internet J. Third World Med. 1, 27-33 (2003).

34. Kosaka, S. et al. Urban-rural difference in the determinants of dietary and energy intake patterns: a case study in West Java, Indonesia. PLoS One 13, e0197626 (2018).

35. Zugravu, C.-A. Eating habits and influential factors for mothers and children in Romania. Int. J. Collab. Res. Intern. Med. Public Heal. 4, 0 (2012).

36. Butnariu, M. \& Sarac, I. Functional food. Int. J. Nutr. 3, 7 (2019).

37. Tebeje, N. B., Biks, G. A., Abebe, S. M. \& Yesuf, M. E. Parent's food preference and its implication for child malnutrition in Dabat health and demographic surveillance system; communitybased survey using multinomial logistic regression model: North West Ethiopia; December 2017. BMC Pediatr. 19, 1-10 (2019).

38. Pengpid, S. \& Peltzer, K. Utilization of traditional and complementary medicine in Indonesia: results of a national survey in 2014-15. Complement. Ther. Clin. Pract. 33, 156-163 (2018).

39. Woerdenbag, H. J. \& Kayser, O. Jamu: Indonesian traditional herbal medicine towards rational phytopharmacological use. J. Herb. Med. 4, 51-73 (2014).

40. Cassileth, B. R., Heitzer, M. \& Wesa, K. The public health impact of herbs and nutritional supplements. Pharm. Biol. 47, 761-767 (2009). 